\title{
Physical Therapy for the Horizontal Semicircular Cupulolithiasis: A Prospective Interventional Case Series from an Otoneurology Center in South Rajasthan, India
}

\author{
Ajay Kumar Vats $^{1 \odot}$ Jugal Kishor Sharma² $\quad$ G. D. Ramchandani ${ }^{3}$
}

\footnotetext{
1Department of Medicine and Neurology, Chaudhary Hospital \& Medical Research Centre Private Limited, Udaipur, Rajasthan, India

${ }^{2}$ Department of Medicine, Central Delhi Diabetes Centre, New Delhi, India

${ }^{3}$ Department of Internal Medicine, Daswani Dental College, Kota, Rajasthan, India
}

Ann Otol Neurotol ISO 2021;4:41-50.

\begin{abstract}
Address for correspondence Ajay Kumar Vats, MBBS, MD (Medicine) DM (Neurology), FRCP, Chaudhary Hospital \& Medical Research Centre Private Limited, 472-473, Sector 4, Hiran Magri, Udaipur, Rajasthan, 313002, India (e-mail: vatsneuro@gmail.com).
\end{abstract}

\begin{abstract}
Keywords

- balance diseases

- cupulolithiasis

- head-shaking maneuver

- HSC-BPPV

- supine roll test

Objective This article aims to study the effect of physical therapy in patients of horizontal semicircular cupulolithiasis with results audited in the short term.

Design Nonrandomized prospective interventional study.

Study Sample Four patients with horizontal semicircular cupulolithiasis.

Results All four patients in whom diagnostic supine roll test (carried at least thrice to look for the sustainability as well as the polarity of the nystagmus) elicited apogeotropic horizontal positional nystagmus lasting more than 1 minute were subjected to therapeutic head-shaking maneuver (HSM). The results were audited immediately after the physical therapy, and at 1 hour. Follow-up by telephonic interviews for 4 weeks was done in all patients. Three out of four patients responded to HSM alone. One patient who did not respond to HSM was successfully treated with four other sequent physical therapies.

Conclusion The response of physical therapy for horizontal semicircular cupulolithiasis occasionally indicates the side of the cupula to which otoconial debris is adherent (Cup-U or Cup-C). Occasionally, Cup-C variant of horizontal semicircular cupulolithiasis can be transformed by physical therapy to long posterior arm horizontal semicircular canalolithiasis-a disorder with better established treatment options.
\end{abstract}

\section{Introduction}

Benign paroxysmal positional vertigo (BPPV) is a mechanical disorder of the vestibular membranous labyrinth. The main symptom is sudden vertigo provoked by changes in the position of the head relative to gravity: sitting upright from supine, lying down, and rolling over in bed, looking up, or stooping forward. ${ }^{1,2}$ Symptoms may last for days, weeks, months, or years, or could be recurrent. ${ }^{3}$ BPPV is commonly due to free-floating otoconial debris entering one or more of three semicircular canals from the utricle, which is called canalolithiasis. ${ }^{4,5}$ Uncommonly, it is due to cupulolithiasis, in which otoconial debris adheres to the gelatinous cupula. 3.6,7 Such pathologies result in cupular deflection when the head moves to a certain position, which is secondary to the otoconial debris overcoming the hydrodynamic
Published online September 29, 2021
DOI https://doi.org/ 10.1055/s-0041-1735990 ISSN 2581-9607

\footnotetext{
(C) 2021. Indian Society of Otology.

This is an open access article published by Thieme under the terms of the Creative Commons Attribution-NonDerivative-NonCommercial-License, permitting copying and reproduction so long as the original work is given appropriate credit. Contents may not be used for commercial purposes, or adapted, remixed, transformed or built upon. (https://creativecommons.org/licenses/by-nc-nd/4.0/). Thieme Medical and Scientific Publishers Pvt. Ltd. A-12, 2nd Floor, Sector 2, Noida-201301 UP, India
} 
resistance of the endolymph in canalolithiasis and the cupula becoming heavier in cupulolithiasis. ${ }^{8}$ In either case, it results in asymmetrical stimulation of the vestibular labyrinth in situations when the head moves relative to gravity, which explains the symptom of positionally triggered vertigo. ${ }^{9}$

- Table 1 shows that 1.94 to 38\% of all BPPV patients diagnosed at any specialty clinic have horizontal semicircular canal BPPV (HSC-BPPV). ${ }^{10-22}$ The supine roll test (SRT) elicits horizontal positional nystagmus (PN) in HSC-BPPV. ${ }^{23}$ Apogeotropic PN is ascribed to either cupulolithiasis or canalolithiasis in the ampullary short anterior arm, ${ }^{24-26}$ with cupulolithiasis being categorized as either Cup-C or Cup-U depending on the side to which otoconial mass is adherent. ${ }^{6,27}$ Geotropic PN is seen with nonampullary long posterior arm horizontal semicircular canalolithiasis. ${ }^{28}$ Both will present bilaterally during SRT. The duration of the PN is up to 1 minute in the long posterior arm horizontal semicircular canalolithiasis and more than 1 minute in the cupulolithiasis. The current diagnostic criteria for horizontal semicircular cupulolithiasis (HSC-BPPV-Cu) require that an apogeotropic horizontal PN elicited during SRT lasts more than a minute and remains unchanged during repetitive testing. ${ }^{29,30}$

Cupulolithiasis was first reported in 1969 as a granular basophilic mass attached to the cupula of the posterior semicircular canal in the temporal bone histological sections of two patients ${ }^{31}$ but a clinico-physiologic basis of its existence in the HSCs generating a long-duration, nearly nonfatigable apogeotropic horizontal PN during SRT was elaborated much later. ${ }^{6,729}$ In the last decade, seven prospective interventional studies $^{32-38}$ have addressed patients with the apogeotropic variant of HSC-BPPV but only two $0^{34,36}$ out of these seven include subjects with exclusive HSC-BPPV-cu, while the oth$\operatorname{ers}^{32,33,35,37,38}$ include those with short anterior arm canalolithiasis as well. Segregation of the cupulolithiasis (Cup-C or Cup-U), and its influence on the treatment of 40 patients with ostensive HSC-BPPV-cu with either one-stage (Cup-U) or two-stage (Cup-C) forced prolonged positioning (FPP) is described by the Chiou et al $^{32}$ but the study possibly includes patients with short anterior arm horizontal semicircular canalolithiasis (duration of the apogeotropic horizontal PN and its unchanging character not specified).

We are reporting a case series of four patients, with HSC-BPPV-cu, who visited our center between June 2019 and July 2020. All four patients were treated with some form of physical therapy, and the results were audited in the short term immediately and after an hour. The resolution of vertigo as well as the disappearance of the apogeotropic PN, during the verifying SRT, was the endpoint of treatment with physical therapy. To the best of the authors' knowledge, no such study of patients diagnosed with HSC-BPPV-cu has been reported from India hitherto.

\section{Material and Methods}

The study was approved by the ethics committee of the attending otoneurology center. The HSC-BPPV-cu was diagnosed as per the following criteria:

1. Rotational vertigo triggered by changes in the position of the head relative to gravity.

2. Apogeotropic horizontal PN elicited by the SRT, the side with the weaker nystagmus was considered pathological as per Ewald's second law. ${ }^{39}$

3. The duration apogeotropic horizontal PN elicited during the SRT lasted more than a minute and its attributes (direction and threshold duration) did not change with at least three times executed SRT.

4. Vertigo associated with the concomitant elicited PN.

Exclusion criteria were: BPPV treated with any form of physical therapy in the past, posttraumatic BPPV, a diagnosis of other peripheral vestibular disorders (Meniere's disease, vestibular neuritis, vestibular paroxysmia, etc.), and vertigo secondary to central nervous system disorders.

Table 1 Pooled data from 13 studies with frequency of different variants of BPPV attending a specialty clinic

\begin{tabular}{|l|l|l|l|l|l|}
\hline Authors & No. of patients & PSC-BPPV & HSC-BPPV & ASC-BPPV & Multiple canals \\
\hline De la Meilleure et al, ${ }^{10} 1996$ & 287 & $78.05 \%$ & $16.38 \%$ & - & $5.57 \%$ \\
\hline Honrubia et al, ${ }^{11} 1999$ & 292 & $85.62 \%$ & $5.14 \%$ & $1.37 \%$ & $7.87 \%$ \\
\hline Macias et al, ${ }^{12} 2000$ & 259 & $93.02 \%$ & $1.94 \%$ & - & $5.04 \%$ \\
\hline Korres et al, ${ }^{13} 2002$ & 122 & $90.16 \%$ & $8.2 \%$ & $1.64 \%$ & - \\
\hline Sakaida et al, ${ }^{14} 2003$ & 50 & $56 \%$ & $38 \%$ & - & $6 \%$ \\
\hline Imai et al, ${ }^{15} 2005$ & 108 & $64.82 \%$ & $33.33 \%$ & - & $1.85 \%$ \\
\hline Nakayama and Epley, ${ }^{16} 2005$ & 833 & $66.39 \%$ & $10.08 \%$ & $2.28 \%$ & $21.25 \%$ \\
\hline Cakir et al, ${ }^{17} 2006$ & 169 & $85.21 \%$ & $11.83 \%$ & $1.18 \%$ & $1.78 \%$ \\
\hline Moon et al, ${ }^{18} 2006$ & 1,692 & $60.9 \%$ & $31.9 \%$ & $2.2 \%$ & $5.0 \%$ \\
\hline Jackson et al, ${ }^{19} 2007$ & 260 & $66.9 \%$ & $11.9 \%$ & $21.2 \%$ & - \\
\hline Chung et al, ${ }^{20} 2009$ & 589 & $61.8 \%$ & $35.3 \%$ & $2.9 \%$ & - \\
\hline Vlastarakos et al, ${ }^{21} 2019$ & 96 & $90.62 \%$ & $8.33 \%$ & $1.04 \%$ & - \\
\hline Chua et al, ${ }^{22} 2020$ & 1,542 & $92.2 \%$ & $3.7 \%$ & - & $4.08 \%$ \\
\hline
\end{tabular}

Abbreviations: ASC-BPPV, anterior semicircular canal benign paroxysmal positional vertigo; HSC-BPPV, horizontal semicircular canal benign paroxysmal positional vertigo; PSC-BPPV, posterior semicircular canal benign paroxysmal positional vertigo. 


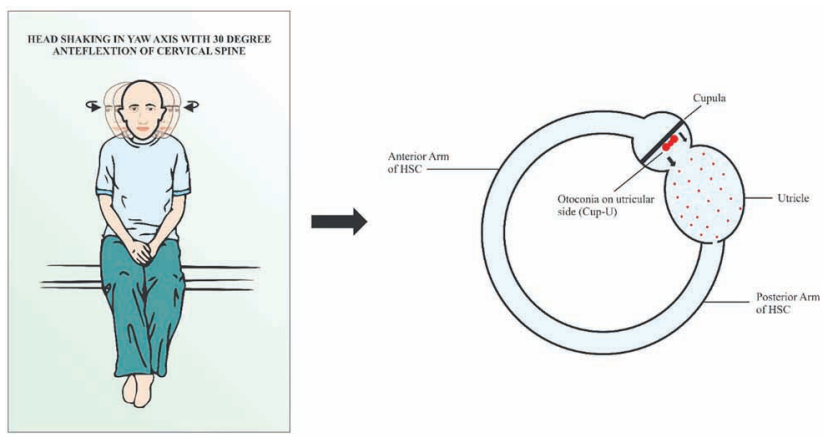

Fig. 1 Head-shaking maneuver (HSM). The head is anteflexed 30 degrees in the pitch plane and briskly shaken by the excursions of 30 degrees side-to-side at an approximate rate of $3 \mathrm{~Hz}$ in the yaw axis for approximately 30 seconds.

Informed consent was taken from all four participants. The general physical examination and vitals of all patients were normal. In all patients, the screening examination of the cervical spine did not reveal any limitation of movement and the examination of the back region did not reveal kyphoscoliosis. The lumbosacral spine assessment, including straight-leg raising (SLR) and reverse SLR tests, were normal in all patients. The neurological examination revealed normal cranial nerve examination; strength was grade $5 / 5$ in all four limbs with normal deep tendon reflexes, and bilateral plantar reflexes were flexor. Examination of the cerebellar system revealed no spontaneous or gaze-evoked nystagmus, and there was no appendicular or axial incoordination. The otoneurological examination revealed normal vertical and horizontal saccadic and smooth pursuit eye movements. The head impulse test was bilaterally normal.

The pathological side is identified by the SRT. The SRT ( - Videos 1, 4, and 7) is done with the patient in long-sitting on the examination table. The patient is moved to supine with her head landing on a four-inch-thick pillow, so it is anteflexed to 30 degrees in this position. The supine neutral position is maintained for 30 seconds to look for lying-down nystagmus (LDN). Thereupon, the patient's head is rotated first to one side and maintained until the elicited PN lasts. After the lateral head roll to one side, the patient's head is brought to the neutral supine position and then briskly rolled in the yaw-axis to the other side, and maintained until the elicited PN lasts. The SRT was performed multiple times (at least three times at an interval of 5 minutes) in all patients to testify the perseverance of its polarity (apogeotropic) as well as its long duration (more than a minute). Immediately after a therapeutic maneuver, and after 1 hour, a verifying SRT was repeated to assess its outcome. The patients were instructed to report next day in case the vertigo recurs. The recovery was audited in terms of the disappearance of vertigo, as well as the previously observed diagnostic apogeotropic horizontal PN. No more than five different therapeutic maneuvers were performed on any one patient in a single day. The therapeutic positional maneuvers and the physical therapies used were as under:

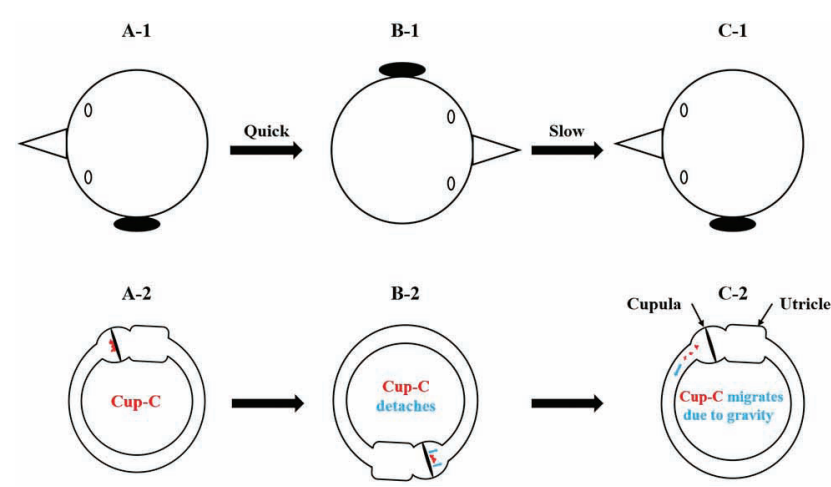

Fig. 2 180-degree head-rolling maneuver in supine recumbent position. With patient in the supine recumbent position, her head is quickly rolled 180 degrees in the yaw axis from the diseased left to the healthy right side. Thereupon, it is slowly rolled back from the healthy right to the diseased left side. Plausibly the quick movement either detaches away or loosens the otoconial debris adherent to the canal side of the cupula (Cup-C) under the influence of generated inertial forces. The slow movement facilitates the migration within the horizontal semicircular canal from its short anterior ampullary arm to the long posterior nonampullary arm under the influence of gravitational force.

HSM ( - Fig. 1) ( - Videos 2, 5, and 8) is performed with the patient in short-sitting and lower limbs hanging along the long edge of the examination table. The head is anteflexed 30 degrees in the pitch plane and briskly shaken by the excursions of 30 degrees side-to-side in the yaw axis for around 30 seconds. Two sequent HSM are done in one session of treatment. The rapid acceleration and deceleration during HSM generate inertial forces in the otoconial debris (irrespective of the side to which it is attached) adherent to the cupula that causes its detachment or loosens it.

Posterosuperior meatal oscillation with a handheld vibrator ( - Video 10) is performed with the patient number 4 in the right lateral recumbent position. Oscillations are delivered to the suprameatal triangle in the posterosuperior area of the involved left ear with an electrically operated handheld vibrator (Hitachi Magic Wand with speeds: low 5,000 revolutions per minute [RPM], high 6,000 RPM) for approximately 60 seconds.

\section{Video 1}

During the initial supine roll test, yawing the head of the patient number 1 to the left, elicited after a latency of $5 \mathrm{sec}$ onds stronger apogeotropic horizontal positional nystagmus that lasted 173 seconds (till the time head remained yawed to the left), and yawing the head to the right elicited after a latency of 4 seconds, a weaker apogeotropic horizontal positional nystagmus that lasted 47 seconds. Online content including video sequences viewable at: https://www.thieme-connect.com/products/ejournals/ html/10.1055-s-0041-1735990-aono-20-25-0132-v1 


\section{Video 2}

Head-shaking maneuver is performed with the patient number 1 in short-sitting and lower limbs hanging along the long edge of the examination table. The head is anteflexed 30 degrees in the pitch plane and briskly shaken by the excursions of 30 degrees side-to-side in the yaw axis for around 30 seconds. Online content including video sequences viewable at: https:// www.thieme-connect.com/products/ejournals/ html/10.1055-s-0041-1735990-aono-20-25-0132-v2

\section{Video 3}

The verifying supine roll test of patient number 1 performed 24 hours after the head-shaking maneuver did not elicit horizontal positional nystagmus on maximal yawing of the head to the right and left and the patient did not complain of vertigo either. Online content including video sequences viewable at: https:// www.thieme-connect.com/products/ejournals/ html/10.1055-s-0041-1735990-aono-20-25-0132-v3

\section{Video 4}

Supine roll test of patient number 2 elicits an apogeotropic horizontal positional nystagmus on yawing the head maximally to the right as well as to the left, which is visibly stronger on the right. The latency of the apogeotropic horizontal positional nystagmus is 4 seconds on either side, and its duration is 190 seconds on the right and 60 seconds on the left side. The characteristics of the apogeotropic horizontal positional nystagmus did not change during several cycles of the diagnostic supine roll test, implying in all probability a pathology of left horizontal semicircular cupulolithiasis. Online content including video sequences viewable at: https://www.thieme-connect.com/products/ejournals/ html/10.1055-s-0041-1735990-aono-20-25-0132-v4

\section{Video 5}

Head-shaking maneuver is performed with the patient number 2 in short-sitting and lower limbs hanging along the long edge of the examination table. The head is anteflexed 30 degrees in the pitch plane and briskly shaken by the excursions of 30 degrees side-to-side in the yaw axis for around 30 seconds.
Online content including video sequences viewable at: https://www.thieme-connect.com/products/ejournals/ html/10.1055-s-0041-1735990-aono-20-25-0132-v5

\section{Video 6}

The verifying supine roll test of patient number 2 performed an hour after the head-shaking maneuver did not elicit any lying down nystagmus or horizontal positional nystagmus on maximal yawing of the head to the right and left and the patient did not complain of vertigo either. Online content including video sequences viewable at: https://www.thieme-connect.com/products/ejournals/ html/10.1055-s-0041-1735990-aono-20-25-0132-v6

\section{Video 7}

During the supine roll test, the patient number 4 is moved from long sitting on the examination table to supine with her head landing on a four-inch-thick pillow resulting in its 30 degrees anteflexion. In the neutral supine position, lying-down nystagmus lasting 26 seconds beating to the patient's left is elicited. Yawing the head to the left as well as right elicits an apogeotropic horizontal positional nystagmus, which is visibly stronger on the right. The duration of the apogeotropic horizontal positional nystagmus is 156 seconds on the right and 60 seconds on the left side. The characteristics of the apogeotropic horizontal positional nystagmus did not change during several cycles of the diagnostic supine roll test, implying in all probability a pathology of left horizontal semicircular cupulolithiasis. Online content including video sequences viewable at: https:// www.thieme-connect.com/products/ejournals/ html/10.1055-s-0041-1735990-aono-20-25-0132-v7

\section{Video 8}

Head-shaking maneuver is performed with the patient number 4 in short-sitting and lower limbs hanging along the long edge of the examination table. The head is anteflexed about 30 degrees in the pitch plane and briskly shaken by the excursions of 30 degrees sideto-side in the yaw axis for approximately 30 seconds. Online content including video sequences viewable at: https://www.thieme-connect.com/products/ejournals/ html/10.1055-s-0041-1735990-aono-20-25-0132-v8 


\section{Video 9}

Immediately after the head-shaking maneuver is carried out in patient number 4 , the verifying supine roll test elicits a left beating lying-down nystagmus lasting 60 seconds in the neutral supine position. The lateral head rolls to the right as well as to the left elicit apogeotropic horizontal nystagmus till the time maximal head yawing is maintained. Elicited apogeotropic horizontal nystagmus is stronger on the lateral head roll to the right. Online content including video sequences viewable at: https://www.thieme-connect.com/products/ejournals/ html/10.1055-s-0041-1735990-aono-20-25-0132-v9

\section{Video 10}

The right lateral recumbent positioning of the patient number 4 is done. Oscillations are delivered to the suprameatal triangle in the posterosuperior area of the involved left ear with an electrically operated handheld vibrator (Hitachi magic wand with speeds: low 5,000 RPM, high 6,000 RPM) for approximately 60 seconds. Online content including video sequences viewable at: https://www.thieme-connect.com/products/ejournals/ html/10.1055-s-0041-1735990-aono-20-25-0132-v10.

\section{Video 11}

Immediately after the left posterosuperior suprameatal oscillation delivered by the handheld electrical vibrator to patient number 4, the verifying supine roll test elicits no lying-down nystagmus in the neutral supine position. The lateral head rolls to the right as well as to the left elicit apogeotropic horizontal nystagmus till the time maximal head is kept yawed. Elicited apogeotropic horizontal nystagmus is stronger on the lateral head roll to the right. Online content including video sequences viewable at: https:// www.thieme-connect.com/products/ejournals/ html/10.1055-s-0041-1735990-aono-20-25-0132-v11

\section{Video 12}

The patient number 4 is positioned supine with her head in 30 degrees of anteflexion on a four-inch-thick pillow. The head-rolling maneuver in the supine position is executed. The head is quickly rolled towards the healthy side, and slowly towards the affected ear for eight times. By the virtue of the generated inertial forces, quick movement is expected to detach the otoconial debris adherent to the cupula on its canal side, and the slow movement is presumed to facilitate the migration of the detached otoconial debris toward the utricle under the effect of gravitational forces. Online content including video sequences viewable at: https://www.thieme-connect.com/products/ejournals/ html/10.1055-s-0041-1735990-aono-20-25-0132-v12

$180^{\circ}$ head-rolling maneuver ${ }^{40}$ (-Fig. 2, - Video 12) is performed with the patient positioned supine with her head in 30 degrees flexion on a four-inch-thick pillow. The head-rolling maneuver in the supine position is executed. The head is quickly rolled towards the healthy side and slowly towards the affected ear eight times. By the generated inertial forces, quick movement is expected to detach the otoconial debris adherent to the cupula on its canal side, and the slow movement is presumed to facilitate the migration of the detached otoconial debris toward the utricle under the effect of gravitational force.

\section{Video 13}

Immediately after alternating quick head rolling for a total of eight times from the diseased left to the healthy right side and slow head rolling from the healthy right to the diseased left side, the verifying supine roll test of patient number 4 elicits lying-down nystagmus of $12 \mathrm{sec}$ onds duration beating to the patient's left in the neutral supine position. The lateral head rolls to the right as well as to the left elicit apogeotropic horizontal nystagmus of more than a minute duration (till the time maximal head yawing is maintained). Elicited apogeotropic horizontal nystagmus is stronger on the lateral head roll to the right. Online content including video sequences viewable at: https://www.thieme-connect.com/products/ejournals/ html/10.1055-s-0041-1735990-aono-20-25-0132-v13

\section{Video 14}

Immediately after forced prolonged positioning (FPP) in the left lateral recumbent position for 1 hour, the verifying supine roll test in patient number 4 elicits lyingdown nystagmus of 28 seconds duration beating to the patient's right in the neutral supine position. The lateral head rolls to the right as well as to the left elicit geotropic horizontal nystagmus of 25 seconds duration to either side. Elicited geotropic horizontal nystagmus is stronger on the lateral head roll to the left Online content including video sequences viewable at: https://www.thieme-connect.com/products/ejournals/ html/10.1055-s-0041-1735990-aono-20-25-0132-v14 


\section{Video 15}

Gufoni maneuver for the transformed left geo-horizontal semicircular canal-benign paroxysmal positional vertigo (HSC-BPPV) is performed by instructing the patient number 4 to be in short siting with both lower limbs hanging down and briskly moving the patient to the right (contralesional) lateral recumbent position and maintaining the latter position for 1 minute (step 1 ). Thereupon, the patient's head is rotated approximately 45 degrees downwards in the yaw-axis and is maintained for 2 minutes (step 2), after which she is positioned upright to the short sitting. Online content including video sequences viewable at: https:// www.thieme-connect.com/products/ejournals/ html/10.1055-s-0041-1735990-aono-20-25-0132-v15

FPP is carried by instructing the patient number 4 to position the left lateral recumbent for an hour. The rationale for left lateral recumbent FPP is to detach the otoconial debris from the canal side of the utricle under the effect of gravitational force ( - Fig. 3). The otoconial debris adherent to the canal side of the cupula is plausibly loosened by the previously executed HSM and 180-degree head-rolling maneuver.

Gufoni maneuver (-Video 15) for the geotropic left HSC-BPPV is performed with the patient number 4 in short sitting with both lower limbs hanging down the examination table. From short sitting, she is positioned right (contralesional) lateral recumbent for a minute. Thereupon, her head is rotated approximately 45 degrees downwards in the yaw-axis and maintained for 2 minutes, after which she is positioned to the upright sitting.

\section{Results}

All four patients included in the study had a history of positionally triggered vertigo on lying supine, rolling to either of the side lateral positions, and on getting upright from the supine. The duration of symptoms ranged from 1 to 8 days. The initial diagnostic SRT elicited apogeotropic horizontal PN of more than a minute duration during the lateral head rolls in all four patients (- Table 2 ). The demographic profile, symptom duration, strength of the PN during diagnostic SRT, LDN direction, diagnosis, therapeutic physical therapy, and results of the verifying SRT are summarized in - Table 3.

\section{Patient Number 1, 2, and 3}

The patient number 1, 2, and 3 underwent therapeutic HSM ( - Fig. 1) with their heads flexed approximately 30 degrees. A verifying SRT performed in all three immediately as well as at 1 hour ( - Videos 3 and $\mathbf{6}$ ) after the HSM did not elicit apogeotropic horizontal nystagmus, and none of them had residual vertigo either. A telephonic interview was weekly taken for the next 4 weeks, and all three remained symptom free.

Table 2 Characteristics of the apogeotropic horizontal positional nystagmus during the initial diagnostic supine roll test

\begin{tabular}{|c|c|c|c|c|c|c|c|}
\hline \multirow{3}{*}{$\begin{array}{l}\text { Patient } \\
\text { number }\end{array}$} & \multicolumn{6}{|c|}{ Diagnostic supine lateral head roll test } & \multirow{3}{*}{$\begin{array}{l}\text { Click for } \\
\text { video }\end{array}$} \\
\hline & \multicolumn{3}{|c|}{ To right } & \multicolumn{3}{|c|}{ To left } & \\
\hline & Latency & Duration & $\begin{array}{l}\text { Relative } \\
\text { strength }\end{array}$ & Latency & Duration & $\begin{array}{l}\text { Relative } \\
\text { strength }\end{array}$ & \\
\hline 1 & $4 \mathrm{~s}$ & $47 \mathrm{~s}$ & Weaker & $5 \mathrm{~s}$ & $173 \mathrm{~s}$ & Stronger & - Video 1 \\
\hline 2 & $4 \mathrm{~s}$ & $190 \mathrm{~s}$ & Stronger & $4 \mathrm{~s}$ & $60 \mathrm{~s}$ & Weaker & -Video 4 \\
\hline 3 & $3 \mathrm{~s}$ & $79 \mathrm{~s}$ & Stronger & $5 \mathrm{~s}$ & $74 \mathrm{~s}$ & Weaker & - \\
\hline 4 & $5 \mathrm{~s}$ & $156 \mathrm{~s}$ & Stronger & $18 \mathrm{~s}$ & $60 s$ & Weaker & - Video 7 \\
\hline
\end{tabular}

Note: The latency, duration, and relative strengths of the apogeotropic horizontal positional nystagmus on lateral head roll to the right and left during the diagnostic supine roll test carried initially.

Table 3 Demographic data, symptom duration, diagnostic supine roll test results with localization (diagnosis) and lateralization, LDN, therapeutic physical therapy, and verifying supine roll tests (immediately after the physical therapy and at 1 hour)

\begin{tabular}{|c|c|c|c|c|c|c|c|c|c|c|}
\hline \multirow[t]{3}{*}{$\begin{array}{l}\text { Patient } \\
\text { number }\end{array}$} & \multirow[t]{3}{*}{ Age } & \multirow[t]{3}{*}{ Sex } & \multirow[t]{3}{*}{$\begin{array}{l}\text { Vertigo } \\
\text { duration }\end{array}$} & \multirow{2}{*}{\multicolumn{2}{|c|}{$\begin{array}{c}\text { Supine roll test } \\
\text { (diagnostic) } \\
\text { Apogeotropic } \\
>1 \text { min }\end{array}$}} & \multirow[t]{3}{*}{ Diagnosis } & \multirow[t]{3}{*}{ LDN } & \multirow{3}{*}{$\begin{array}{l}\text { Physical } \\
\text { therapy for } \\
\text { treatment }\end{array}$} & \multicolumn{2}{|c|}{$\begin{array}{l}\text { Supine roll test } \\
\text { (verifying) }\end{array}$} \\
\hline & & & & & & & & & \multirow[t]{2}{*}{ Immediate } & \multirow[t]{2}{*}{ At 1-h } \\
\hline & & & & Right & Left & & & & & \\
\hline 1. & 40 & $\mathrm{~F}$ & $1 \mathrm{~d}$ & + & ++ & Right apo-HSC-BPPV & Absent & HSM & No PN & No PN \\
\hline 2. & 25 & $\mathrm{~F}$ & $8 d$ & ++ & + & Left apo-HSC-BPPV & Absent & HSM & No PN & No PN \\
\hline 3. & 51 & $\mathrm{~F}$ & $2 d$ & ++ & + & Left apo-HSC-BPPV & Absent & HSM & No PN & No PN \\
\hline 4. & 64 & $\mathrm{~F}$ & $4 d$ & ++ & + & Left apo-HSC-BPPV & To left & See -Fig. 4 & No PN & No PN \\
\hline
\end{tabular}

Abbreviations: +, weaker; ++, stronger; apo-HSC-BPPV, apogeotropic horizontal semicircular canal benign paroxysmal positional vertigo; F, female; HSM, head-shaking maneuver; LDN, lying-down nystagmus; PN, positional nystagmus. 


\section{Patient Number 4}

The long-duration horizontal apogeotropic PN (-Video 7) with perseverance on repeating the supine lateral head roll test suggests HSC-BPPV-cu. Cupulolithiasis of the left HSC is indicated by the side eliciting the weaker horizontal PN during the supine lateral head roll test as per the Ewald's second law. ${ }^{39}$ Accordingly, the patient underwent two sequent HSM ( - Fig. 1, - Video 8). A verifying SRT ( - Video 9) immediately after the HSM remains unchanged. The right lateral recumbent positioning of the patient is done. Mastoid oscillations (-Video 10) are delivered to the suprameatal triangle in the posterosuperior area of the involved left ear with an electrically operated handheld vibrator for approximately 60 seconds. Immediately after the mastoid oscillation, a second verifying SRT ( - Video 11 ) remains almost unaltered. A 180-degree head-rolling maneuver (-Fig. 2, -Video 12) was undertaken. Plausibly the quick movement during the 180-degree head-rolling maneuver either detaches away or loosens the otoconial debris adherent to the canal side of the cupula (Cup-C) under the influence of generated inertial forces. The slow movement facilitates the migration within the HSC from its short anterior arm to the long posterior arm under the influence of gravitational force. However, a third verifying SRT (-Video 13) immediately after the 180 -degree head rolling maneuver remains still unaltered. Thereupon, the patient is positioned left lateral recumbent for 1 hour (FPP) ( - Fig. 3). A fourth verifying SRT ( - Video 14) elicits LDN of 28 seconds duration beating

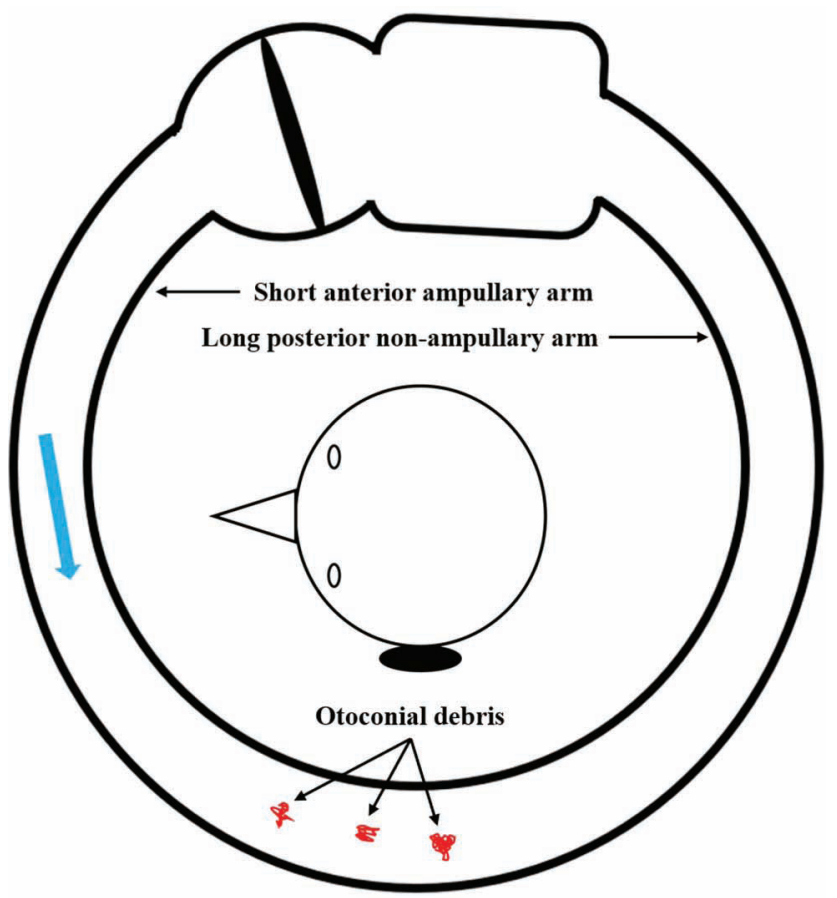

Fig. 3 Forced prolonged positioning (FPP) in left lateral recumbent position for 1 hour. The patient is positioned left lateral recumbent for 1 hour. In the left lateral recumbent FPP, the otoconial debris (in red), which has either detached or loosened from the canal side of the cupula, migrates (blue arrow) within the short ampullary anterior arm of the canal toward its posterior end. to the patient's right in the neutral supine position. The lateral head rolls to the right as well as to the left elicit geotropic horizontal nystagmus of 25 seconds duration to either side. Elicited geotropic horizontal nystagmus is stronger on the lateral head roll to the left, indicating transformation to left long posterior arm horizontal semicircular canalolithiasis. Two sequent Gufoni maneuvers (-Video 15) are undertaken. A fifth verifying SRT (-Video 16) performed immediately, and after 1 hour neither elicited the PN nor the patient had vertigo. A telephonic interview was weekly taken for the next 4 weeks, and the patient remained symptom free. The treatment protocol of patient number 4 is summarized in -Fig. 4.

\section{Video 16}

The verifying supine roll test of the patient number 4 an hour after the Gufoni maneuver did not elicit any lying-down nystagmus or horizontal positional nystagmus on maximal yawing of the head to the right and left, and the patient did not complain of vertigo either Online content including video sequences viewable at: https://www.thieme-connect.com/products/ejournals/ html/10.1055-s-0041-1735990-aono-20-25-0132-v16

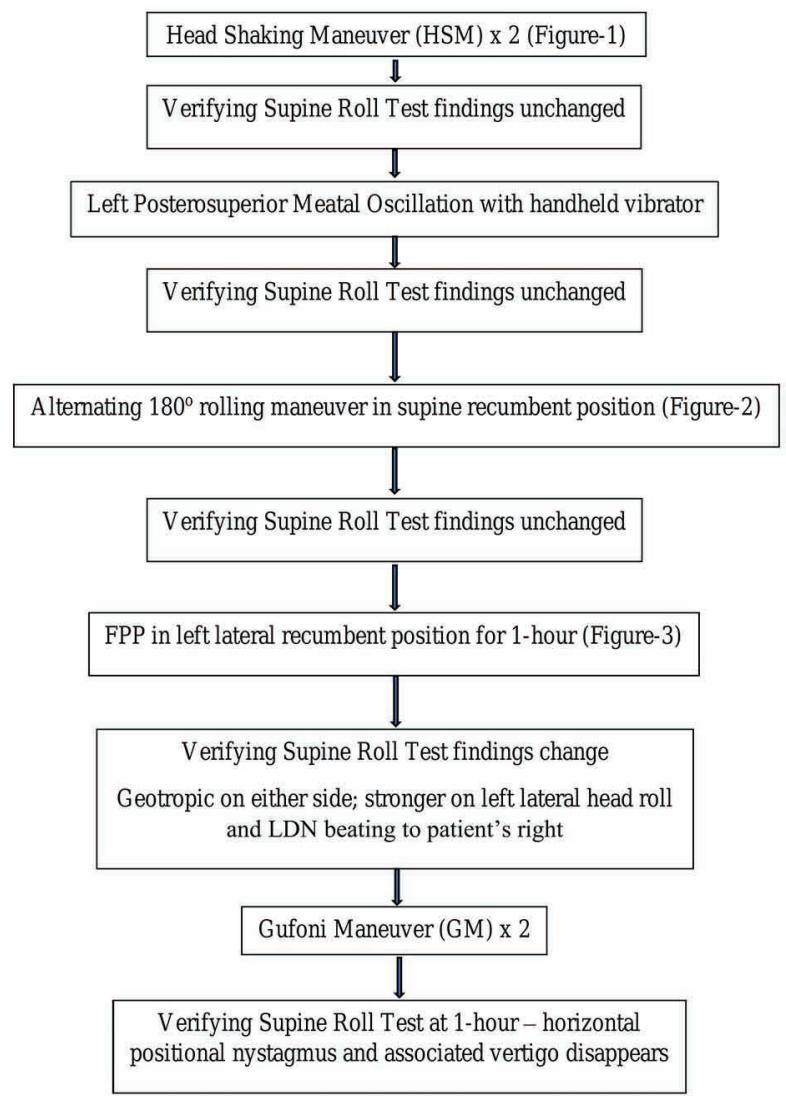

Fig. 4 Management algorithm of patient number 4 with Cup-C variant of left horizontal semicircular cupulolithiasis. 


\section{Discussion}

The apogeotropic variant of the HSC-BPPV is attributable to pathologies at three different sites within the HSC, namely (1) ampullary short anterior arm canalolithiasis, (2) Cup-U variant of cupulolithiasis, and (3) Cup-C variant of cupulolithiasis. A singular assessment of the apogeotropic horizontal PN by the SRT is often inadequate to decipher the precise location of the otoconial debris. The apogeotropic horizontal PN that either disappears or transforms into the geotropic variant, during SRT, is in all probability secondary to an unfixed and moveable otoconial debris within the short anterior arm of the HSC. ${ }^{24,41-44}$ By contrast, apogeotropic horizontal PN secondary to cupulolithiasis (heavy cupula) invariably lasts more than a minute and remains unaltered even after multiple sequences of the SRT. ${ }^{29,30}$ For this reason, performing multiple sequences of the diagnostic SRT is imperative to establish a diagnosis of HSC-BPPV-cu, and this was aptly executed in all four cases reported here.

Cases 1 to 3 responded immediately to HSM. Verifying SRT immediately and after 1 hour did not elicit apogeotropic horizontal PN, and all three remained symptom free over 4 weeks of follow-up on interviewing telephonically. HSM employs the inertia of the otoconial debris to disengage it from the gelatinous cupula. The offloading of the otoconial debris from the utricle side of the cupula would bring immediate relief in vertigo, ${ }^{23}$ and the detached debris disperses into the gelatinous matrix of the utricle ( - Fig. 1). The dramatic response in patients 1 to 3 to HSM in terms of alleviation of positionally triggered vertigo as well as extirpation of the apogeotropic PN (immediately as well as after 1 hour) explicitly endorse the fact that they suffered from the Cup-U variant of HSC-BPPV-Cu.

Case 4 failed to respond to the two sequent HSM. Accordingly, we had to recourse to a series of sequent maneuvers generating the inertial forces to disengage the otoconial debris adherent to the cupula; mastoid oscillation and 180-degree head-rolling maneuver, previously reported in the literature. ${ }^{34,38}$ Because of the failure of HSM and mastoid oscillation to abolish the apogeotropic horizontal PN and the concomitant positionally triggered vertigo, it was hypothetically inferred that otoconial debris is adherent to the canal side of the cupula. The 180-degree head-rolling maneuver ( - Fig. 2) and its variants have been used previously with variable success to offload the otoconial debris purportedly adherent to the canal side of the cupula. ${ }^{40,43,45}$ The 180-degree head-rolling maneuver, and the antecedent HSM and mastoid oscillation plausibly loosened the otoconial debris adherent to the canal side of the cupula. A subsequent left lateral recumbent FPP ( - Fig. 3 ) for 1 hour just dropped off the otoconial debris loosely adherent to the canal side of the cupula under the effect of the gravitational force. A verifying SRT executed just after the FPP elicits an LDN to the patient's right, and geotropic horizontal PN on the lateral head roll to either side that was visibly stronger on the left side. Such a change in the polarity of the horizontal PN from apogeotropic to geotropic and reversal in the lateralization of its strength (stronger on the lateral head roll to right initially to stronger on the lateral head roll to left now) indicates transformation from Cup-C cupulolithiasis to long posterior arm canalolithiasis of the left HSC. The otoconial debris not only dropped off from the canal side of the cupula after the left lateral recumbent FPP but also relocated to the posterior arm of the HSC. Based on our case series, we suggest an algorithm for action when an apogeotropic horizontal PN is elicited on SRT ( - Fig. 5).

\section{Conclusion}

HSC-BPPV-cu is a distinct disorder of the membranous vestibular labyrinth. Not merely the lateralization but the identification of the side of the cupula to which otoconial debris is adherent has a bearing on its management. The physical therapy and maneuvers either employ the inertial forces generated by the maneuvers (e.g., HSM, mastoid oscillation,

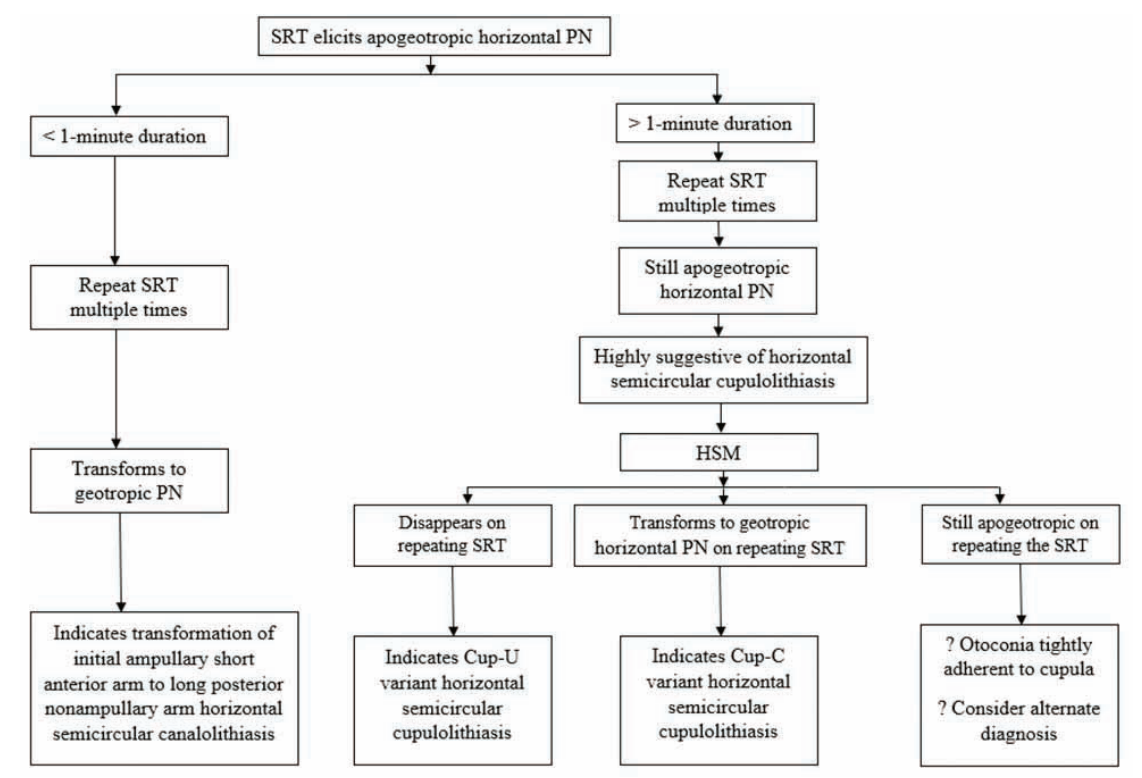

Fig. 5 Suggested algorithm for action when supine roll test (SRT) elicits apogeotropic horizontal positional nystagmus. 
23 Lee SH, Kim JS. Benign paroxysmal positional vertigo. J Clin Neurol 2010;6(2):51-63

24 Nuti D, Vannucchi P, Pagnini P. Benign paroxysmal positional vertigo of the horizontal canal: a form of canalolithiasis with variable clinical features. J Vestib Res 1996;6(3):173-184

25 Vannucchi P, Pecci R. About nystagmus transformation in a case of apogeotropic lateral semicircular canal benign paroxysmal positional vertigo. Int J Otolaryngol 2011;2011:687921

26 Pérez-Vázquez P, Franco-Gutiérrez V. Treatment of benign paroxysmal positional vertigo. A clinical review. J Otol 2017;12(4):165-173

27 Bruintjes TD, Masius-Olthof S, Kingma H. Benign paroxysmal positional vertigo of the horizontal canal. Clin of Otorhinolaryngology 2017;1(1):7-14

28 Asprella Libonati G. Diagnostic and treatment strategy of lateral semicircular canal canalolithiasis. Acta Otorhinolaryngol Ital 2005;25(5):277-283

29 Casani A, Giovanni V, Bruno F, Luigi GP. Positional vertigo and ageotropic bidirectional nystagmus. Laryngoscope 1997;107(6):807-813

30 von Brevern $\mathrm{M}$, Bertholon $\mathrm{P}$, Brandt $\mathrm{T}$, et al. Benign paroxysmal positional vertigo: diagnostic criteria. J Vestib Res 2015;25(3-4):105-117

31 Schuknecht HF. Cupulolithiasis. Arch Otolaryngol 1969; 90(6):765-778

32 Chiou WY, Lee HL, Tsai SC, Yu TH, Lee XX. A single therapy for all subtypes of horizontal canal positional vertigo. Laryngoscope 2005;115(8):1432-1435

33 Boleas-Aguirre MS, Pérez N, Batuecas-Caletrío A. Bedside therapeutic experiences with horizontal canal benign paroxysmal positional vertigo (cupulolithiasis. Acta Otolaryngol 2009;129(11):1217-1221

34 Kim SH, Jo SW, Chung WK, Byeon HK, Lee WS. A cupulolith repositioning maneuver in the treatment of horizontal canal cupulolithiasis. Auris Nasus Larynx 2012;39(2):163-168

35 Kim JS, Oh SY, Lee SH, et al. Randomized clinical trial for apogeotropic horizontal canal benign paroxysmal positional vertigo. Neurology 2012;78(3):159-166
36 Yamanaka T, Sawai Y, Murai T, Okamoto H, Fujita N, Hosoi H. New treatment strategy for cupulolithiasis associated with benign paroxysmal positional vertigo of the lateral canal: the head-tilt hopping exercise. Eur Arch Otorhinolaryngol 2014;271(12):3155-3160

37 Zuma e Maia F. New treatment strategy for apogeotropic horizontal canal benign paroxysmal positional vertigo. Audiology Res 2016;6(2):163

38 Kim HA, Park SW, Kim J, et al. Efficacy of mastoid oscillation and the Gufoni maneuver for treating apogeotropic horizontal benign positional vertigo: a randomized controlled study. J Neurol 2017;264(5):848-855

39 Ewald JR, Physiologische Untersuchungen Ueber das Endorgan de Nervus Octavus. Wiesbaden, Germany: Bergmann JF Publishers; 1892

40 Califano L, Melillo MG, Mazzone S, Vassallo A. Converting apogeotropic into geotropic lateral canalolithiasis by head-pitching manoeuvre in the sitting position. Acta Otorhinolaryngol Ital 2008;28(6):287-291

41 Ciniglio Appiani G, Catania G, Gagliardi M, Cuiuli G. Repositioning maneuver for the treatment of the apogeotropic variant of horizontal canal benign paroxysmal positional vertigo. Otol Neurotol 2005;26(2):257-260

42 Califano L, Melillo MG, Mazzone S, Vassallo A. "Secondary signs of lateralization" in apogeotropic lateral canalolithiasis. Acta Otorhinolaryngol Ital 2010;30(2):78-86

43 Casani AP, Vannucci G, Fattori B, Berrettini S. The treatment of horizontal canal positional vertigo: our experience in 66 cases. Laryngoscope 2002;112(1):172-178

44 Vannucchi P, Libonati GA, Gufoni M. The physical treatment of lateral semicircular canal canalolithiasis. Audiol Med 2005;3(1):52-56

45 Nuti D, Agus G, Barbieri MT, Passali D. The management of horizontal-canal paroxysmal positional vertigo. Acta Otolaryngol 1998;118(4):455-460

46 Bhattacharyya N, Gubbels SP, Schwartz SR, et al. Clinical practice guideline: benign paroxysmal positional vertigo (update. Otolaryngol Head Neck Surg 2017;156(3_suppl):S1-S47 